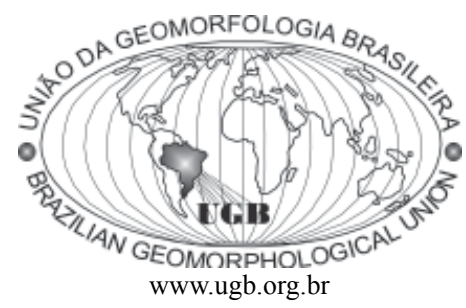

\title{
APLICAÇÃO DO ÍNDICE DE HACK (SL) A UM TRECHO DO RIO ZÊZERE, PORTUGAL
}

\author{
Daniel Vieira Souza \\ M.Sc. Geógrafo - Centro de Ciências Agrárias, Departamento de Solos, Av.PH Rolfs s/n, Centro, \\ Universidade Federal de Viçosa, Minas Gerais, CEP 36571-000 - e-mail: danielgeoufv@yahoo.com.br
}

António Antunes Martins

Prof. PhD. Centro de Geofísica - Departamento de Geociências, R. Romão Ramalho, 59, Universidade de Évora, Portugal, CEP 7000-671 -e-mail: aam@uevora.pt

André Luiz Lopes de Faria

Prof. D.Sc. Centro de Ciências Humanas Letras e Artes, Departamento Geografia, Av. PH Rolfs s/n, Centro, Universidade Federal de Viçosa, Minas Gerais, CEP 36571-000 - e-mail: andre@ufv.br

\begin{abstract}
Resumo
Os perfis longitudinais de rios são sensíveis a movimentações tectônicas causando alterações no nível de base. Devido a isto, verifica-se incisão fluvial a montante de compartimentos abatidos e agradação a jusante de compartimentos levantados. Os canais fluviais são dinâmicos e se modificam através da incisão e da agradação periódicas, o estudo destes processos revestese de grande importância na compreensão das alterações do relevo. A formação de vales encaixados com perfis típicos em $V$, ou o aparecimento de trechos de agradação pode ter origem em causas tectônicas, ou outras. Hack (1973) propôs um índice (stream-gradient index) para detectar estas alterações em cursos fluviais, decorrentes de mudanças no substrato geológico, aporte de carga, ou tectonismo. O stream-gradient index, ou simplesmente índice SL, relação declive (slope) vs. comprimento do curso (length). O presente trabalho objetiva identificar rupturas de declive, num trecho do rio Zêzere, afluente do rio Tejo. O rio Zêzere corre num vale encaixado no interior da Cordilheira Central Portuguesa. Para identificar as roturas de declive utilizou-se o perfil longitudinal, índice de Hack, SL (slope VS. Lenght). Como resultado foi possível detectar locais onde sofreram abatimentos tectônicos, principalmente entre Pedrógão e Bogas de Baixo, foi possível também observar a influência de processos de erosão diferencial e de soleiras Quartzíticas de Farjão a Sarzedas na regularização dos processos tectônicos a montante daqueles níveis de base locais.
\end{abstract}

Palavras-chave: Índice de Hack, rio Zêzere, Neotectônica.

\begin{abstract}
The longitudinal outlines of the Rivers are very sensible to tectonics movements, causing changes in the level of base. Because of this we verify a fluvial incision at the pillar of the compartments and an aggradation to the justant of the raising compartments. The fluvial channels are dynamics and modify trough the incision and from the periodic aggradations, the study of these process are very important to understand the changing of the relieves. The formations of valleys fitted in typical outline in $\mathrm{V}$, or the appearance of stretch of aggradations, probably has its origin in tectonics causes, or others. Hack (1973) proposed an index (stream-gradient index) to detect these changings at the river course, due to changes of the geological substract, the input of load or tectonics. The stream gradient index or just SL index a relation between slope versus the length of the river course. The present project has the purpose of identify the ruptures of downhill, in a stretch of the Zezerê River affluent of Tejo River. The Zezerê River flows in a valley fitted at the Central Portuguese Mountain Range .To identify the downhill ruptures,
\end{abstract}


we use the longitudinal outline, Hack Index, SL (Slope vs. Length). As a result it was possible to detect the places that has suffered tectonic abatement, mainly between Pedrógãoo and Bogas de Baixo, it were also possible to observe the influence of the differential erosion process and the quartzitics rocks of Farjão to Sarzedas in the regularization of the tectonics process to the above of that local base level.

Keywords: Hack Index, Zêzere river, Neotectonic.

\section{Introdução}

A definição de movimentos neotectônicos é bastante controversa, já que não existe um consenso entre os diversos especialistas deste domínio. Primeiramente, foram considerados movimentos neotectônicos os movimentos da crosta afetando depósitos e superfícies do Terciário Superior ou do Quaternário e que tiveram uma intervenção fundamental na gênese da topografia contemporânea. Posteriormente, foi postulada a ausência de períodos definidos, causando uma quebra de fronteira, ocasionando uma abrangência de seu conceito para qualquer movimento de deformação em nível geodésico, indo de idades de $10^{7}$ anos até os movimentos sísmicos da atualidade, incorporando a esses estudos todas as deformações tectônicas da crosta (Orogênese, Epirogênese e tensões crustais diversas). Primeiramente, foram considerados movimentos neotectônicos os movimentos da crosta afetando depósitos e superfícies do Terciário Superior ou do Quaternário, e que tiveram uma intervenção fundamental na gênese da topografia contemporânea (Mescherikov, Y.A., 1948).

Os movimentos crustais em margens continentais pouco ativas são difíceis de serem observados diretamente, havendo a necessidade de utilizar métodos adequados que ressaltem os seus efeitos na paisagem. A análise morfológica é um método que resulta do processo de dedução de alterações na paisagem, as quais podem ser expressas através de gradientes morfométricos originados através de processos exógenos, capazes de produzir alterações morfológicas. Os cursos de água tendem a buscar seu equilíbrio, que é expresso pela relação entre a capacidade de carregar sedimentos e a competência em escavar seu vale, os canais fluviais sofrem interferência de vários processos morfológicos, entre eles, os processos tectônicos que ocasionam alterações no seu perfil longitudinal.

Merritts et al., (1994) baseando-se em perfis longitudinais de rios, ressalta a sua importância para a detecção de deformações tectônicas, da influência do eustatismo e para investigação de terraços fluviais na costa norte da Califórnia.

Em 1973 Hack propôs um índice para detectar alterações nos cursos de água, decorrente de mudanças no substrato geológico, aporte de carga, ou tectonismo, chamado de stream-gradient index, ou simplesmente índice SL (relação declive, slope vs. comprimento de curso, length) FIGURA 1 , sendo aplicado com sucesso na definição de fenômenos neotectônicos em diversos contextos geológicos.

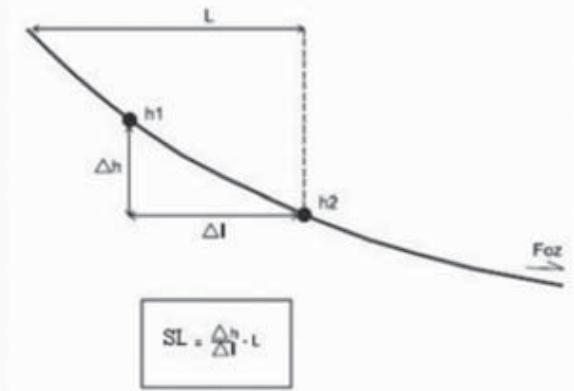

Figura 1 - Cálculo do indice SL para segmento de drenagem utilizando. L comprimento da drenagem, $\Delta h=$ diferença de altitude entre duas isoipsas $\Delta l=$ projeção horizontal do comprimento do segmento de drenagem entre duas isoípsas. (Modificado de Etchebehere 2000).

Este índice baseia na razão entre a declividade de um determinado trecho de um canal, multiplicada pela projeção horizontal deste trecho medido desde a cabeceira da drenagem até ao ponto mais a jusante do trecho do canal objeto de análise (Etchebehere 2004).

Chen et al. 2006 utilizaram o índice de Hack para detectar deformações crustais na região centro-oeste de Taiwan. Etchebehere 2004 analisa o índice SL, chamado por ele em seu trabalho de RDE (Relação Declividade Extensão) para detecção de áreas de deformações neotectônicas na Bacia do rio Peixe, em São Paulo, fazendo uma comparação com o seu perfil longitudinal, como uma de suas conclusões ele identifica que onde os índices "fugiam" da média o perfil se caracterizava por zonas de rupturas no canal.

Torbjon (1999) utilizou perfis longitudinais no estudo da evolução dos terraços fluviais de origens eustáticas durante a última glaciação. Goldrick (2006) efetuou uma análise entre o índice de Hack e do perfil de equilíbrio em beedrock stream como referência empírica a perfis longitudinais, em uma área no SE da Austrália caracterizada por uplifts durante o Neógeno.

Neste trabalho foram utilizados dois índices morfométricos; o perfil longitudinal do curso de água e o índice de Hack SL (slope vs. lenght), para a determinação de roturas de declive que podem ter sua gênese vinculada a deformações crustais. Ao longo de uma parte do rio Zêzere, situado no Maciço Hespérico, na Zona Centro Ibérica de Portugal. 


\section{Caracterização da Área de Estudo}

O rio Zêzere é o maior afluente do rio Tejo, nasce no Covão da Ametade na Serra da Estrela e passa pelas vilas de Manteigas, Orvalho e Pedrógão Pequeno e deságua em Constância no médio Tejo Português. Terá a sua formação iniciada no Mioceno Superior a cerca de 10 milhões de anos atrás durante a era Cenozóica, onde começaram os primeiros movimentos de deformações crustais, que foram de forma contínua dando origem à elevação da montanha (Ferreira, 1999).

As principais unidades geológicas presentes na região do Zêzere são: (i)Rochas graníticas de idade Varisca; (ii) rochas Metassedimentares de idade Pré-cambriana; (iii) depósitos aluvionares e glaciários do quaternário. A tectônica da área é denominada pela megaestrutura regional designada por zona de falha, de Bragança-Vilariça-Manteigas (FBM) a qual corresponde a um desligamento esquerdo que constitui um dos mais importantes movimentos crustais do sistema tardi-varisco de fraturas do noroeste ibérico, formando Rifts e Gabrens (Afonso, 2006).

O vale do Zêzere tem sua origem na formação de vales glaciais que no passado ocupavam a região e desciam diretamente do planalto central. Suas vertentes foram desenvolvidas pelo processo de crioclastia, havendo bastantes rupturas nas rochas, podendo ser encontrados testemunhos e morainas a poucos quilômetros de Manteigas (Ferreira, 1999).

Segundo Ribeiro (1980), parte do curso do Zêzere possivelmente fixou-se por epigenia, sobre os depósitos aluvionares que transbordam da bacia do baixo Tejo e por antecedência na borda do Maciço Antigo no bloco da Estrela. Seu traçado geral sugere uma origem tectônica, suas sinuosidades e divagações do curso do rio excluem a hipótese de um vale estabelecido em linhas de fraqueza ou fraturas, possivelmente o Zêzere se estabeleceu em um fosso de abatimento intermédio (Gabren) que separa em dois Hosrts secundários o Horst principal da cordilheira.

Próximo a Orvalho encontram-se cristas quartzíticas (que seguem de Fajão até Sarzedas durante $35 \mathrm{~km}$ ) que podem ser consideradas como cristas apalachianas com vestígios de aplainação mais ou menos conservados, formadas ou acentuados durante o encaixe da drenagem, que separa em dois tipos a paisagem. A montante de Orvalho, por influência das soleiras de rochas quartzíticas desenvolveu-se meandros dessimétricos formados pelo encaixe da drenagem, onde a taxa de migração lateral supera a taxa de incisão vertical. A jusante originou-se meandros de trincheira derivados de meandros livres que depois se encaixaram sem pouco desenvolvimento sendo quase simétricos, notam-se também sinuosidades que parecem ser orientadas por fraturas transversais. Nas cristas quartzíticas o rio passa por gargantas imponentes e no entorno de Pedrógão o rio apresenta seus vales bastante encaixados quase a pique. (Ribeiro, 1990).

\section{Material e Método}

Para mensurar as deformações crustais advindas de processos tectônicos, utilizou-se o perfil longitudinal do rio; índice de Hack, SL (slope VS. lenght); e uma análise visual qualitativa do modelo digital de elevação para observar a mudança do padrão do relevo e espacialização dos dados, para compará-los com os resultados obtidos.

Os dados morfométricos foram extraídos através de medições nas cartas planialtimétricas de números: 254, 255, 265 e 266 em formato analógico do Serviço Geográfico Militar de Portugal em uma escala de 1:25.000, utilizando-se curvímetro digital. A partir da extração dos dados, foi organizado um banco de dados geográficos para que posteriormente pudesse ser espacializado e a partir de então foi gerado o perfil longitudinal do rio e o gráfico do gradiente SL.

O perfil longitudinal do rio foi derivado através de medições nas cartas planialtimétricas do Serviço Geográfico Militar de Portugal em uma escala de 1:25.000 em formato de papel utilizando a metodologia descrita em Guerra 2000.

O índice de Hack ou índice SL (relação slope vs. length), Molin 2004, Frankel 2002, se refere à variação da declividade de um determinado trecho de um rio normalizada pela distância do referido trecho às cabeceiras e possibilita a análise de rios e de trechos selecionados, propiciando as bases para o estabelecimento de comparações entre cursos d'água de ordem e de porte diferentes, este índice pode ser extraído de duas formas, SL (global), aqui utilizado e SL (local), sendo o Global, calculado apenas pra o rio principal de um canal, e o SL local calculado para todos seus afluentes, sendo possível determinar o grau de estabilidade tectônica e fazer um mapeamento mais detalhado.

O índice SL pode ser calculado da seguinte forma: $S L$ $=(\Delta \mathrm{h} / \Delta \mathrm{l}) . L($ Fig. 1$)$ onde, $\Delta \mathrm{h}$ é a diferença altimétrica entre dois pontos extremos de um segmento ao longo do curso d'água; $\Delta \mathrm{l}$ é a projeção horizontal da extensão do referido segmento $(\Delta \mathrm{h} / \Delta \mathrm{l}$ corresponde ao gradiente da drenagem naquele trecho); e L corresponde ao comprimento total do curso d'água a montante do ponto para o qual o índice SL está sendo calculado (Etchebhere, 2004).

Assim como Cheng (2006), neste trabalho utilizou-se como ferramenta os sistemas de informações geográficas, fazendo-se uso dos dados do SRTM obtidos no site: www. mariland.com para a construção de um Modelo Digital de Elevação (MDE). Para digitalização do curso de água utilizou-se uma cena Landsat MSS que cobria toda a área de estudo, também disponível no mesmo sítio. Também foi utilizado um mosaico de imagens Quickbird obtidas no Software Google Earth apenas para observação do terreno o que possibilitou a visualização de afloramentos rochosos.

Originalmente os dados SRTM obtidos contém um pixel de $90 \mathrm{~m}$. Para que fosse construído o MDE os dados foram interpolados para que se obtivesse um Grid com tamanho de pixel de $10 \mathrm{~m}$, obtendo curvas de nível com esta equidistância assim como Wobus (2003), para depois disto ser feito o MDE utilizando o Software ArcGis 9.2. 
O MDE será utilizado apenas para a visualização da mudança do padrão de relevo da região (quer sendo bastante acidentado e com pequenos vales fluviais, apresentando muitas escarpas, quer apresentando terraços mais largos e um relevo mais suave) juntamente com a espacialização da variação dos valores dos índices morfométricos analisados.

\section{Resultados e Discussões}

A interpolação do SRTM para um pixel com $10 \mathrm{~m}$, mostra-se eficiente para ressaltar os aspectos do relevo, visto que o modelo fica mais apurado e sensível a variações altimétricas, o que possibilita fazer uma boa aproximação de sua compartimentação, segundo os modelos de ciclo geográfico geomorfológico além da possível comparação com o resultado do índice $S L$.
Ao analisar o MDE (Figura 2) observa-se que a jusante de Silvares indo até próximo a Bogas de Baixo, o rio assume um traçado meândrico, com planícies fluviais e ocorrência de vários meandros abandonados. Na parte centro sul do MDE próximo a Orvalho, nota-se uma paisagem bem distinta, sendo o relevo bastante acidentado devido à presença de cristas quartzíticas. O rio Zêzere apresenta-se meândrico com seu vale encaixado com seu perfil típico em $\mathrm{V}$ em grande parte de seu percurso e algumas vezes encachoeirados e sem meandros abandonados. Observa-se então duas paisagens com características geomorfológicas distintas, com sua história de formação contemporâneas, formada no Mioceno quando ocorreram os primeiros movimentos crustais que deformaram a região, soerguendo a Serra da Estrela e regiões adjacentes situadas na ZCI, inseridas em uma região pediplanada conhecida como Meseta Ibérica.

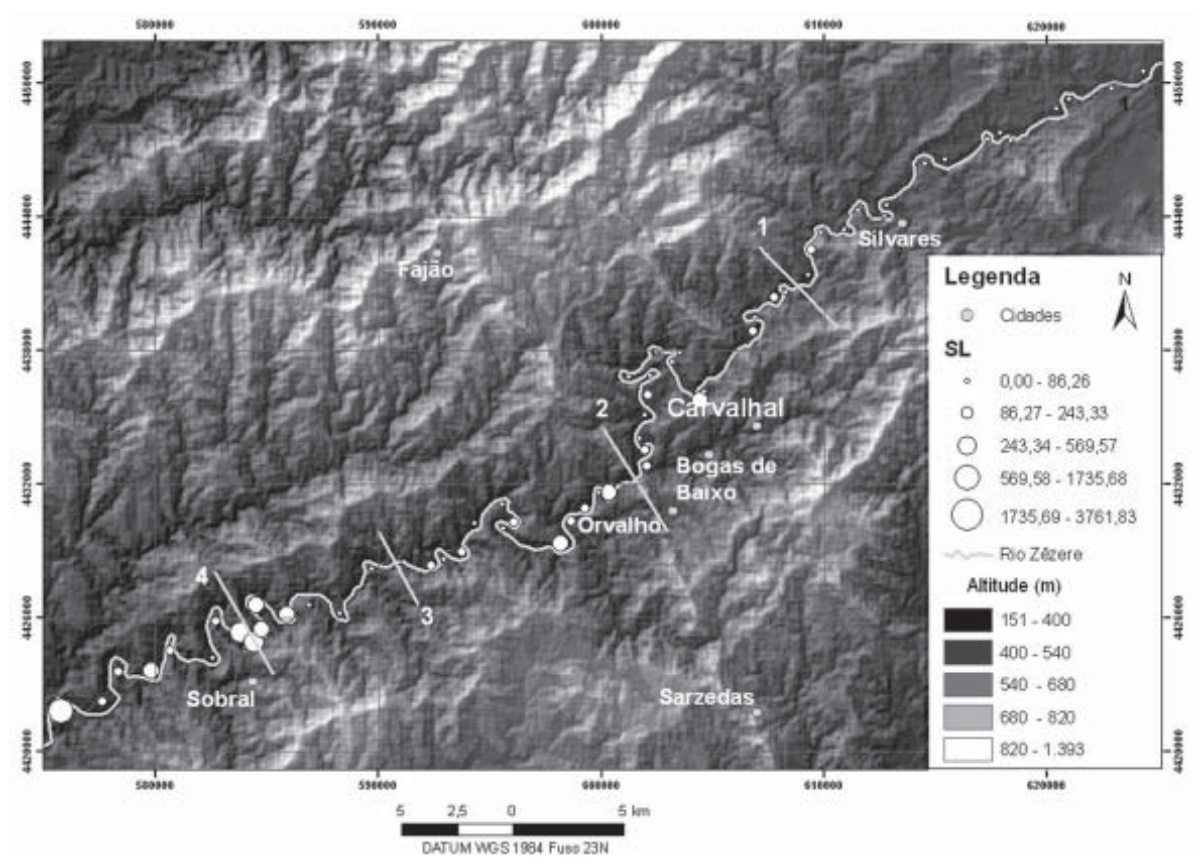

Figura 2 - Modelo Digital de Elevação, com a espacialização do índice SL.

Na figura 2 observam-se quatro transectos e a partir deles foram delineados quatro perfis topo-

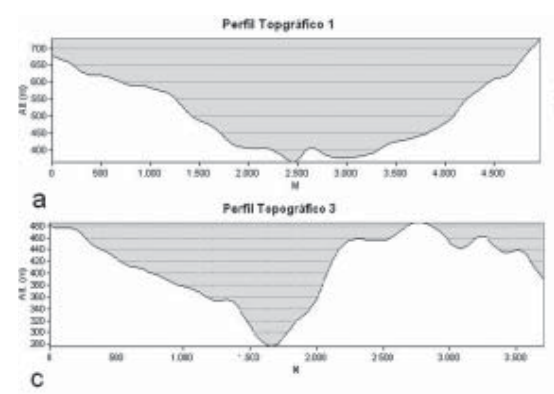

gráficos em diferentes contextos geomorfológicos (Gráfico 1).

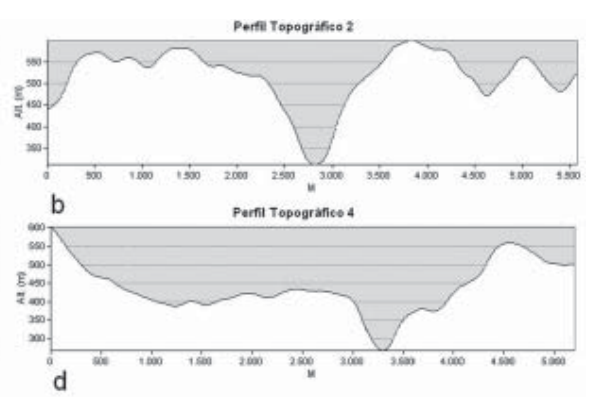

Grafico1 - Perfis topográficos: a - Trecho de Silvares a Bogas de Baixo onde rio apresenta planícies fluviais e meandros abandonados onde o leito do rio mostra-se mais aberto; $b$ - Sobre as cristas Quartzíticas de Sarzedas a Fajão onde o rio não apresenta planícies e seus terraços encontram-se bem encaixados; $c$-Vertentes sobre xistos onde o vale do rio encontra-se encaixado; $d$-Vertentes sobre xistos - apresentam seu perfil tipico em $V$. 
O perfil 1 localiza-se na área entre Silvares e Bogas de Baixo, onde o rio assume um traçado meândrico, seus vales fluviais ganham extensão e na paisagem são encontrados diversos meandros abandonados. O perfil 2 foi delineado sobre as cristas quartzíticas de Orvalho, situado entre Sarzedas e Fajão, esta rocha é resistente a erosão, o que contribui para originar topos agudos e recortados. É possível observar o alinhamento de seus cumes. O perfil 3 apresenta-se mais encaixado que o perfil 1 e menos encaixado que o perfil 2 , seria uma situação intermediária, onde o rio assume uma morfologia meandrante, não apresentando planícies fluviais, e com seus terraços bem encaixados. Sua geologia é influen- ciada pelo metamorfismo da Serra da Estrela, responsável pelo desenvolvimento dos xistos, que tende a originar formas do relevo mais suavizadas. O perfil longitudinal 4 apresenta uma situação parecida com o perfil 3 no entanto com suas vertentes mais encaixadas e sem terraços.

Ao observar o seu perfil longitudinal percebe-se que apresenta algumas rupturas em seu curso. No gráfico 2 na figura a, são destacadas as quebras mais abruptas, possivelmente tendo sua origem quando uma região aplainada é atingida por algum rápido movimento tectônico, ocasionando alterações em seu nível de base.
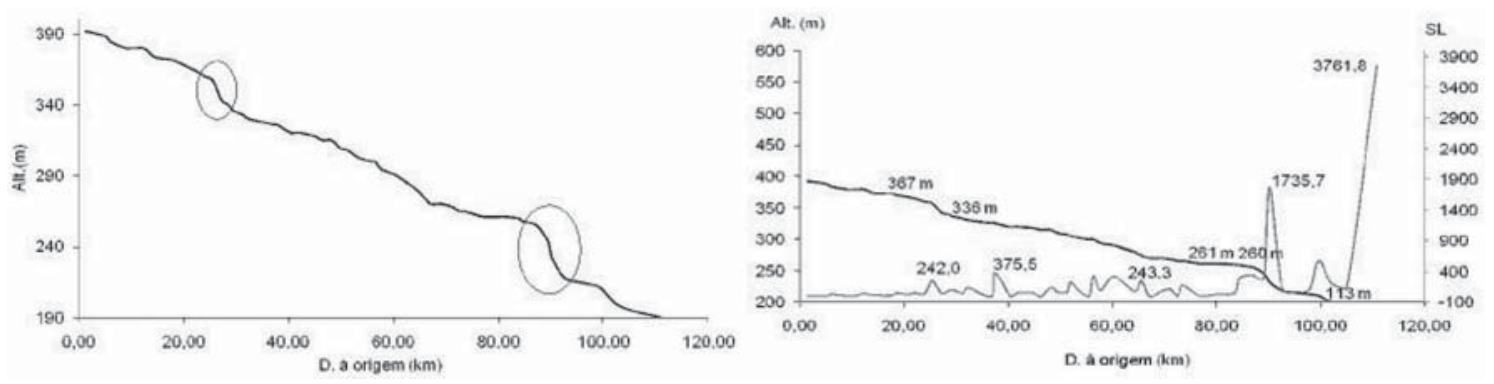

Gráfico 2 - a - Perfil Longitudinal com o eixo y em escala log, b - Índice SL e Perfil longitudinal.

Ao observar o gráfico 2 figuras a e b, que representam os dados referentes ao perfil longitudinal e o índice SL o sobrepondo, nota-se que onde os valores do índice SL apresentam maior discrepância entre si, coincidem com as áreas de rupturas do perfil longitudinal, e onde os menores valores são encontrados, coincidem com locais onde seu traçado assume um comportamento mais retilíneo. É curioso verificar que a montante das cristas quartzíticas de Orvalho, os índices SL são bem inferiores ao que se encontram a jusante. Este fato sublinha a importância das soleiras de rochas resistentes na regularização dos trechos dos rios a montante daqueles níveis de base locais.

\section{Conclusão}

A análise morfométrica aqui delineada se mostrou eficiente na identificação de rupturas de declive devidas a possíveis deformações tectônicas, migração de vagas de erosão regressivas ou devido a causas litológicas. A utilização dos métodos empregados possibilitou concluir que o rio Zêzere sofreu influências de processos neotectônicos durante sua gênese, o que influenciou no estabelecimento de ruturas em seu perfil longitudinal, o tornando encaixado e meândrico, que mesmo com o passar dos tempos suas marcas ainda permanecem na paisagem, principalmente nas ruturas entre Alvaro e Pedrógão, e na rutura de declive a cerca de 5 $\mathrm{km}$ a montante da Serra do Carregal, sendo ambos os locais identificados com valores de índice SL, acima da média do entorno, no entanto no ponto acima da Serra do Carregal, merece um olhar mais detalhado com auxílio de mapa geológico, visto que está próximo de uma zona de transição entre dois compartimentos geomorfológicos distintos, sendo o compartimento a montante mais influenciado por processos glaciais da Serra da Estrela.

A manutenção de índices SL em valores mais baixos entre as cristas quartzíticas de Orvalho vem sublinhar a importância da erosão diferencial e de soleiras de rochas na regularização dos trechos a montante do rio, atuando como "controladores" do nível de base local. Apesar da necessidade de estudos detalhados utilizando-se de mapas geológicos, os resultados encontrados podem contribuir para futuros processos de planejamento para a bacia, já que a ocupação do solo em áreas com as características físicas da bacia do rio Zêzere, com tectônica ativa pode vir a ser complicada.

\section{Referências Bibliográficas}

AFONSO, M.J, MARQUES, J.E, MARQUES, J.M, CARREIRA, P.M, FONSECA, P.E, GOMES, A, CARVALHO MARTINS, J, SAMPER, J., BORGES, F. S., ROCHA, F.T. CHAMINÉ, H.I., (2006). Caracterização multidisciplinar dos recursos hídricos subterrâneos em áreas urbanas e montanhosas (Norte e Centro de Portugal): Metodologias e técnicas. Actas do II Fórum Ibérico de águas engarrafadas e termalismo. Porto 2006 Disponível em: http://www.lattex.fc.ul. pt/Lattex_Publ.htm acessado em Julho 2007. 
CHRISTOFOLETTI, Antônio, 1936 - Geomorfologia. São Paulo, Edgard Blucher, $2^{\circ}$ ed. 1980

CHENG, S. QIDONG. D, ZHOU, S. YANG, G. Strath terraces os Jinshaan Canyon, Yellow River, and Quaternary tectonic movements os the Plateau, Nort China, Editora Terra Nova, n.14, vol.4 p.215-224, 2002

CHEN, Yen-Chieh. SUNG, Quocheng, CHEN, Chao-Nan. JEAN, Jiil-Shuh. Variation in tectonic activities of the central and southwestern foothills, Taiwan, inferred from river hack profiles. Terr. Atmos. Ocean. Sci., Vol. 17, No. 3, 563-578, September 2006

ETCHEBHERE, Mario Lincoln. Terraços neoquaternários no vale do Rio do Peixe, Planalto Ocidental Paulista: implicações estratigráficas e tectônicas. Rio Claro, 2000 2v. Tese (Doutorado em Geociências) - Instituto de Geociências e Ciências Exatas, Universidade Estadual Paulista.

ETCHEBHERE, Mario Lincoln, FULFARO, José Vicente, PERINOTTO, José Alexandre de Jesus, Aplicação do Índice "Relação declividade-extensão RDE" na bacia do Rio do Peixe (SP) para detecção de deformações Neotectônicas; Revista do Instituto de Geociências - USP Geologia USP Série Científica, São Paulo, v.4 n.2, p. 43-56 outubro 2004

FERREIRA, N. VIEIRA, G. - 1999 - Guia geológico e geomorfológico do Parque Natural da Serra da Estrela. Locais de interesse geológico. Instituto Geológico e Mineiro e Instituto da Conservação da Natureza.

FRANKEL.L. Kurt. Quantitative topographic differences between erosionally exuhumed and tectonically active mountain fronts: Implications for late-Cenozoic evolution of the southern Rocky Moutains. A Tesis Presented to the Graduate and Research Committee of Lehigh University in Candidact for the Degree os Master os Science in Geological Sciences. May 3, 2002
GUERRA, Antônio José Teixeira. CUNHA, Sandra Baptista da. Geomorfologia: uma atualização de bases e conceitos. $3^{\circ} \mathrm{Ed}$. Rio de Janeiro, Bertrand Brasil, 1998.

GOLDRICK, Geoff, BISHOP, Paul. Regional analysis of bedrock stream long profiles: evaluation of Hack's SL form, and formulation and assessment of an alternative (the DS form). Earth Surface Processes and Landforms Published online 5 September 2006 in Wiley InterScience (www.interscience.wiley.com) DOI: 10.1002/esp.1413.

JARVIS A., H. I. REUTER, A. NELSON, E. GUEVARA, 2006. Hole-filled seamless SRTM data v3, International Centre for Tropical Agriculture (CIAT), disponível em http://srtm.csi. cgiar.org

HACK, J. T. Stream-profile analysis and stream-gradient index. J. Res. Geol. Survey, 429p. 1973

MERRITTS, J.D. VINCEN, K.R. WOHL, E.E. Long river profiles, tectonism and eustasy: A guide to interpreting fluvial terraces. Journal of geophysical Research, Vol. 99. NO. B7 July 10, 1994.

MESCHERICOV, Y. A.(1968). Neotectonics. In: the Encyclopedia of Geomorphology, R.W. Fairbridge (Ed). Dowden, Hutchinson and Ross, Inc. Stroudsbourg, Pensilvânia, 773p.

MOLIN, Paola, FRANK J, Pazzaglia. DRAMIS, Francesco. Geomorphic Expression of Active Tectonics in a Rapidly-Deforming forearc, sila massif, Calabria Southern Italy. American journal of Sience, Vol.304, September, 2004, p.559-589.

RIBEIRO, Orlando. Opúsculos Geográficos. III: Aspectos da Natureza, Fundação Calouste Gulbenkian, Lisboa, 1990, 356 p.

WOBUS, Cameron WHIPPLE, K. KIRBY, E. SNYDER, N. JHONSON, J. SYPYROPOLOU, K. CROSBY, B. SHEEHAN, D., in press (2005), Tectonics From Topography: Procedures, promise and pitfalls, GSA Penrose Publication: Tectonics, Climate and Erosion, 2003. 